\title{
Genome organization of epidemic Acinetobacter baumannii strains
}

Pier Paolo Di Nocera ${ }^{1 *}$, Francesco Rocco ${ }^{1}$, Maria Giannouli ${ }^{2}$, Maria Triassi ${ }^{2}$ and Raffaele Zarrilli ${ }^{2^{*}}$

\begin{abstract}
Background: Acinetobacter baumannii is an opportunistic pathogen responsible for hospital-acquired infections. A. baumannii epidemics described world-wide were caused by few genotypic clusters of strains. The occurrence of epidemics caused by multi-drug resistant strains assigned to novel genotypes have been reported over the last few years.

Results: In the present study, we compared whole genome sequences of three A. baumannii strains assigned to genotypes ST2, ST25 and ST78, representative of the most frequent genotypes responsible for epidemics in several Mediterranean hospitals, and four complete genome sequences of A. baumannii strains assigned to genotypes ST1, ST2 and ST77. Comparative genome analysis showed extensive synteny and identified 3068 coding regions which are conserved, at the same chromosomal position, in all A. baumannii genomes. Genome alignments also identified 63 DNA regions, ranging in size from $40126 \mathrm{~kb}$, all defined as genomic islands, which were present in some genomes, but were either missing or replaced by non-homologous DNA sequences in others. Some islands are involved in resistance to drugs and metals, others carry genes encoding surface proteins or enzymes involved in specific metabolic pathways, and others correspond to prophage-like elements. Accessory DNA regions encode 12 to $19 \%$ of the potential gene products of the analyzed strains. The analysis of a collection of epidemic $A$. baumannii strains showed that some islands were restricted to specific genotypes.

Conclusion: The definition of the genome components of $A$. baumannii provides a scaffold to rapidly evaluate the genomic organization of novel clinical A. baumannii isolates. Changes in island profiling will be useful in genomic epidemiology of A. baumannii population.
\end{abstract}

\section{Background}

The genus Acinetobacter comprises 26 species with valid names and nine genomic species with provisional designations that were defined by DNA-DNA hybridization. Acinetobacter baumannii, A. pittii and A. nosocomialis are the three species more frequently associated with human diseases [1-3]. A. baumannii is the species that is more frequently isolated in hospitalized patients, especially in intensive-care-unit (ICU) wards. The capability to survive in dry conditions and resistance to disinfectants and antimicrobial agents contribute to the selection of $A$. baumannii in the hospital setting [1,2].

\footnotetext{
*Correspondence: dinocera@unina.it; rafzarri@unina.it

${ }^{1}$ Dipartimento di Biologia e Patologia Cellulare e Molecolare, Università Federico II, Via S. Pansini 5, 80131 Napoli, Italy

${ }^{2}$ Dipartimento di Scienze Mediche Preventive, Sezione di Igiene, Università

Federico II, Via S. Pansini 5, 80131 Napoli, Italy

Full list of author information is available at the end of the article
}

Epidemics caused by multidrug-resistant (MDR) strains of $A$. baumannii were reported in several hospitals worldwide and shown to be caused by A. baumannii strains resistant to all classes of antimicrobials including carbapenems, exhibiting variable resistance to rifampicin and tigecycline, but still susceptible to colistin $[2,4]$. Outbreaks were caused by clusters of highly similar $A$. baumannii strains that were assigned by several genotypic methods to three main international clonal lineages initially named European clones I, II and III [1,2,4-6], and now are referred to as international clones I, II and III, respectively $[7,8]$. The predominance of international clone II lineage world-wide and the occurrence of hospital outbreaks caused by MDR strains belonging to novel genotypes not related to the three main clonal complexes have been reported during the last few years [4,8-10].

\section{Biomed Central}


We have recently reported [11] the draft genome sequences of three A. baumannii strains, 3990, 4190 and 3909, respectively assigned to ST (sequence types) 2, 25 and 78, which are representative of the most frequent genotypes responsible for epidemics occurred in Mediterranean hospitals [9]. Here we compare the genomes of the 3990, 4190 and 3909 strains and the genomes of four wholly sequenced MDR A. baumannii strains, two assigned to ST1, one each to ST2 and ST77. Data helped to define core and auxiliary genome components of the $A$. baumannii genomes.

\section{Results}

Features of the genome of ST2 3990, ST25 4190 and ST78 3909 strains

The draft genome sequences of the ST2 3990, ST25 4190 and ST78 3909 strains, isolated during cross-transmission episodes occurred at the Monaldi Hospital, Naples, Italy between 2006 and 2009, comprised 4,015,011 bases, 4,032,291 bases and 3,954,832 bases, and generated $3,806,3,910$ and 3,721 protein coding sequences by automated annotation against $A$. baumannii AB0057 genome, respectively [11]. The ST25 4190 strain contained two plasmids, p1-ABST25 and p2ABST25, that both carry one copy of the carbapenemhydrolyzing oxacillinase (CHDL) bla $a_{\text {OxA-72 }}$ a gene which encodes a protein identical but for a single amino-acid substitution to the product of the bla $a_{\mathrm{OXA}-24}$ gene. The ST2 3990 strain contained also two plasmids, p1-ABST2 carrying a complete tra locus, and p2-ABST2 carrying one copy of the CHDL bla $a_{\text {OXA-58 }}$ gene. p1-ABST2 and p2-ABST2 were homologous to plasmids pACICU2 and pACICU1 identified in the ST2 ACICU strain [12], respectively. While p1-ABST2 and pACICU2 are almost identical, p2-ABST2 shares only two third of the coding sequences with pACICU1. The plasmid p1-ABST78 identified in the ST78 3909 strain shares approximately $80 \%$ of the coding sequences, including the $b l a_{\text {OXA-58 }}$ gene, with plasmid pACICU1 (Additional files 1 and 2). The different plasmids were classified using the PCRtyping procedure recently described [13]. A conserved scaffold that includes four/five direct perfect repeats that can be defined as "iterons", and the gene encoding the replicase repAci1 belonging to the Rep-3 superfamily and assigned to the GR2 homology group, was found in plasmids pACICU1, p2ABST2, p2ABST25 and p1ABST78. The repAciX replicase (Rep-3 superfamily, GR10 homology group) is encoded by plasmids pACICU1 and p2ABST2, the Aci6 replicase (GR6 homology group) by pACICU2 and p1ABST2 plasmids. A protein identical to the replicase encoded by plasmid pMMA2 carrying the bla $a_{\text {OXA-24 }}$ gene [14], is encoded by p1ABST25. While sharing common sequences, all plasmids exhibited a mosaic genetic structure that might have been generated by multiple recombination events. The hypothetical gene products encoded by the plasmids found in the A. baumannii strains 3990, 3909 and 4190 are listed in Additional file 2.

\section{The $A$. baumannii chromosome}

Making use of the Mauve software [15], the proteins putatively encoded by the draft genomes of the $A$. baumannii strains 3990, 3909 and 4190 [11] were compared to the ORFs encoded by the wholly sequenced genomes of the A. baumannii AB0057 and AYE strains assigned to ST1, ACICU strain assigned to ST2, ATCC17978 strain assigned to ST77 [12,16-18].

A. baumannii genomes exhibit extensive synteny. Sequence comparisons revealed that 3068 coding regions are conserved, at the same chromosomal position, in the compared A. baumannii genomes. A file including all conserved gene products is available upon request. Genes encoding proteins shown or hypothesized to be important for pathogenicity are conserved in the analyzed strains at the same relative chromosomal position (Table 1). The set includes OmpA, the outer membrane protein which has role in biofilm formation [19] and induces, when secreted, death of epithelial and dendritic cells [20], the DD-endopeptidase, which contributes to the resistance of $A$. baumannii to bactericidal activity presumably by remodelling the cell surface [21], phospholipase D, an enzyme crucial for proliferation in human serum [22], proteins involved in the formation of capsule [23], type I pili [24], and iron metabolism [25]. According to the published annotation, OmpA, DD-endopeptidase, phospholipase D, and many other deduced gene products are smaller in ATCC 17978 as compared to their orthologs. Size differences do not denote allelic variation, but are determined by the criteria adopted to select the initiating methionine in ATCC17978 ORFs.

Multidrug resistance is a key feature of $A$. baumannii and several genes have a role in establishing a MDR phenotype. Genes encoding efflux pumps and resistance proteins shown or hypothesized [26] to be involved in the process are conserved in all strains. In contrast, genes encoding drug-inactivating and drug-resistant enzymes reside in accessory DNA regions which are present only in some strains (Table 2). Among these, are worth of mention the extended spectrum beta-lactamase $V E B-1$ gene, found in the AYE genome, the bla $a_{\text {OXA-20 }}$ class D beta-lactamase gene, found in the ACICU and 3990 genomes, both assigned to ST2 genotype, the CHDL genes bla $a_{\text {OXA-23 }}$, found in the AB0057

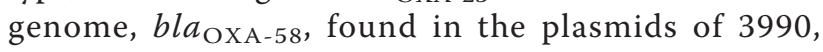
ACICU and 3909 strains, and bla $a_{\text {OXA-72 }}$ found in the plasmids of 4190 strain, respectively. Promoter sequences within flanking insertion sequences likely 
Table 1 Gene products involved in pathogenicity in A.baumannii genomes

\begin{tabular}{|c|c|c|c|c|c|c|c|}
\hline \multirow[t]{2}{*}{ Gene products } & \multicolumn{7}{|c|}{ Strains } \\
\hline & AB0057 & AYE & 3990 & $\mathrm{ACICU}$ & 4190 & ATCC17978 & 3909 \\
\hline \multicolumn{8}{|l|}{ capsule formation } \\
\hline tyrosine kinase Ptk & 91 & 3818 & 936 & 71 & 3295 & 49 & 2600 \\
\hline Tyrosine phosphatase Ptp & 92 & 3817 & 935 & 72 & 3296 & 50 & 2601 \\
\hline \multicolumn{8}{|l|}{ type I pili formation } \\
\hline CsuE & 2565 & 1324 & 787 & 2414 & 3382 & 2213 & 744 \\
\hline CsuD & 2566 & 1323 & 786 & 2415 & 3383 & 2214 & 745 \\
\hline CsuC & 2567 & 1322 & 785 & 2416 & 3384 & 2215 & 746 \\
\hline CsuB & 2568 & 1321 & 784 & 2417 & 3385 & 2216 & 747 \\
\hline CsuA & 2569 & 1320 & 783 & 2418 & 3386 & 2217 & 748 \\
\hline CsuA/B & 2570 & 1319 & 782 & 2420 & 3387 & 2218 & 3415 \\
\hline \multicolumn{8}{|l|}{ iron metabolism } \\
\hline nonribosomal peptide synthetase BasD & 2811 & 1095 & 2421 & 2579 & tblastn & 2383 & 1389 \\
\hline nonribosomal peptide synthetase BasC & 2812 & 1094 & 2420 & 2580 & 3813 & 2384 & tblastn \\
\hline ferric acinetobactin receptor & 2813 & 1093 & 2419 & 2581 & 3814 & 2385 & 3376 \\
\hline ferric acinetobactin transport system periplasmic binding protein & 2814 & 1092 & 2418 & 2582 & 3815 & 2386 & 3375 \\
\hline ferric acinetobactin transport system ATP-binding protein & 2815 & 1091 & 2417 & 2583 & 3816 & 2387 & 3374 \\
\hline ferric acinetobactin transport system permease & 2816 & 1090 & 2416 & 2584 & 3817 & 2388 & 3373 \\
\hline ferric acinetobactin transport system permease & 2817 & 1089 & 2415 & 2585 & 3818 & 2389 & 3372 \\
\hline \multicolumn{8}{|l|}{ hemin utilization } \\
\hline biopolymer transport protein ExbD/TolR & 1827 & 2051 & 351 & 1629 & 227 & 1063 & 1994 \\
\hline biopolymer transport protein ExbD/TolR & 1828 & 2050 & 352 & 1630 & 228 & 1064 & 1993 \\
\hline biopolymer transport protein & 1829 & 2049 & 353 & 1631 & 229 & 1065 & 1992 \\
\hline TonB family protein & 1830 & 2047 & 354 & 1632 & 230,231 & $3708^{*}$ & 1991 \\
\hline TonB-dependent receptor & 1831 & 2046 & 355 & 1633 & 232 & 1606,1607 & 1990, 1989 \\
\hline heme-binding protein A & 1832 & 2045 & 358 & 1634 & 234 & 1608 & 1987 \\
\hline heme-binding protein A & 1833 & 2044 & 359 & 1635 & 235 & 1609 & 1986 \\
\hline Zn-dependent oligopeptidase & 1834 & 2043 & 360 & 1636 & 236 & 1610 & 1985 \\
\hline ABC-type dipeptide/oligopeptide/nickel transport system permease component & 1835 & 2042 & 361 & 1637 & 237,238 & 1611 & 1984 \\
\hline ABC-type dipeptide/oligopeptide/nickel transport system permease component & 1836 & 2041 & 362 & 1638 & 239 & 1612 & 1983 \\
\hline glutathione import ATP-binding protein GsiA & 1837 & 2040 & 363 & 1639 & 3719 & 1613 & 1982 \\
\hline
\end{tabular}

* The asterisk indicates one of the 436 proteins putatively encoded by ATCC17978 not included in the GenBank:NC_009085 file. tblastn refer to unannotated 4190 and 3909 proteins identified by tblastn searches.

influence the expression of many of these resistance genes. Interestingly, the majority of the genomes harbour mutations in $g y r A$ and/or parC genes.

Shared synteny lets to represent the A. baumannii chromosomes as $4 \mathrm{Mb}$ long DNA segments homologous to each other throughout their lengths (Figure 1). DNA tracts, ranging in size from 4 to $126 \mathrm{~kb}$, are present in one or more strains, but missing or replaced by alternative DNA segments in others (see vertical bars in Figure 1). Some of these regions correspond to DNA sequences earlier suspected to be mobile because found in $A$. baumannii but not in A. baylyi DNA or vice versa $[17,27]$. Specific $15-36 \mathrm{~kb}$ regions are missing in all strains but AB0057 (see triangles in Figure 1), and may therefore plausibly correspond to strain-specific deletions. Many of the accessory genomic DNA segments exhibit characteristic features of genomic islands, such as the presence of insertion sequences at one end, a GC content different from the bulk chromosome, insertion within tRNA or non-coding RNA genes, target site duplications (TSDs) at the ends formed upon genome integration $[28,29]$. For sake of simplicity, all the accessory DNA regions have been called GEnomic Islands (GEIs). GEIs found at the 63 variable loci identified in the $A$. baumannii genomes, and some of their properties, are diagrammatically reported in Figure 2. TSDs flanking GEIs are reported in Additional file 3, and GEI gene products are listed in Additional file 4. In text and figures individual GEIs are referred by the locus number and the strain acronym used in Figure 2. Core and accessory chromosomal DNAs are fully conserved in ACICU and 3990 strains. Because of this, only the ACICU GEIs are shown in Figure 2. In draft genomes some GEIs reside in different contigs. The colinearity of 
Table 2 Antimicrobial resistance gene products encoded by A.baumannii genomes

\begin{tabular}{|c|c|c|c|c|c|c|c|}
\hline \multirow[t]{2}{*}{ Gene Products } & \multicolumn{7}{|c|}{ Strains } \\
\hline & AB0057 & AYE & 3990 & $\mathrm{ACICU}$ & 4190 & ATCC17978 & 3909 \\
\hline Class $C \beta$-lactamase & 9,2796 & 1110 & 2437 & 2564 & 2076 & 2367 & 1404 \\
\hline \multirow[t]{2}{*}{ Class A $\beta$-lactamase } & $283($ TEM-1) & - & - & - & - & - & - \\
\hline & - & 3623 (VEB-1) & - & - & - & - & - \\
\hline \multirow[t]{5}{*}{ Class D $\beta$-lactamase } & $\begin{array}{c}1757 \\
(\text { oxa-69) }\end{array}$ & 2122 (оха-69) & 2827 (оха-66) & $\begin{array}{l}1560 \text { (oxa- } \\
66)\end{array}$ & 63 (oxa-64) & $\begin{array}{c}1517 \\
(\text { oxa-95) }\end{array}$ & 1089 (oxa-90) \\
\hline & - & - & 3514 (oxa-20) & $\begin{array}{l}0226 \text { (oxa- } \\
20 \text { ) }\end{array}$ & - & - & - \\
\hline & $\begin{array}{c}0551 \\
(\text { oxa-23)* }\end{array}$ & - & - & - & - & - & - \\
\hline & - & - & $\begin{array}{l}\text { p2ABST2 } \\
(\text { oxa-58)* }\end{array}$ & $\begin{array}{c}\text { pACICU1 } \\
(\text { oxa-58) } \\
(2 X)\end{array}$ & $\begin{array}{l}\text { p1ABST25 } \\
(\text { oxa-72)* }\end{array}$ & - & $\begin{array}{l}\text { p1ABST78 } \\
(\text { oxa-58)* }\end{array}$ \\
\hline & - & - & - & - & $\begin{array}{l}\text { p2ABST25 } \\
(\text { oxa-72)* }\end{array}$ & - & - \\
\hline $\begin{array}{c}\text { AAC (3)-I aminoglycoside } \\
\text { acetyltransferase }\end{array}$ & 291 & 3573 & - & - & - & - & - \\
\hline $\begin{array}{c}\text { AAC }\left(6^{\prime}\right)-I \text { aminoglycoside } \\
\text { acetyltransferase }\end{array}$ & - & 3630 & 3516 & 223 & - & - & - \\
\hline \multirow{2}{*}{$\begin{array}{l}\text { APH }\left(3^{\prime}\right)-1 \text { aminoglycoside } \\
\text { phosphotransferase }\end{array}$} & 288 & 3578 & - & - & - & - & - \\
\hline & - & - & 3897 & 1948 & 560 & - & - \\
\hline \multirow{2}{*}{$\begin{array}{l}\text { ANT }\left(3^{\prime \prime}\right)-I \text { aminoglycoside } \\
\text { adenylyltransferase }\end{array}$} & 293 & 3570,3618 & - & - & 3268 & - & - \\
\hline & 171 & 3739 & 1641 & 156 & 2954 & 131 & 2919 \\
\hline \multirow[t]{2}{*}{ Chloramphenicol acetyl transferase } & 280 & 3587 & - & - & - & - & - \\
\hline & 3104 & 798 & 3709 & 2932 & 1731 & 2691 & 1443 \\
\hline DNA topoisomerase $\|$ & $3037\left[R^{1}\right]$ & $0867\left[R^{1}\right]$ & $0747\left[R^{1}\right]$ & $2869\left[R^{1}\right]$ & $2907\left[R^{1}\right]$ & $2626[S]$ & $0539\left[R^{1}\right]$ \\
\hline DNA topoisomerase IV & $0232\left[R^{2}\right]$ & $3679\left[R^{2}\right]$ & $1415[\mathrm{~S}]$ & $0214[\mathrm{~S}]$ & $2382\left[R^{2}\right]$ & - & $3413\left[R^{2}\right]$ \\
\hline RNA polymerase $\beta$ Subunit & $0369[\mathrm{~S}]$ & $3489[S]$ & $2179\left[R^{3}\right]$ & $0303[\mathrm{~S}]$ & $3155[\mathrm{~S}]$ & $0287[\mathrm{~S}]$ & $0411[S]$ \\
\hline \multirow[t]{2}{*}{ Dihydropteroate synthase } & 265,294 & $3568,3616,3612$ & 3142 & 228 & - & 675 & - \\
\hline & 3095 & 807 & 3700 & 2923 & 2684 & 2680 & 1433 \\
\hline Dihydrofolate reductase type 1 & - & 3644 & - & - & - & - & - \\
\hline Dihydrofolate reductase type 3 & 540 & 3315 & 3351 & 467 & 3501 & 457 & 403 \\
\hline
\end{tabular}

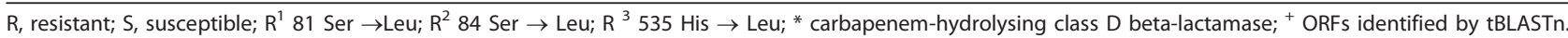

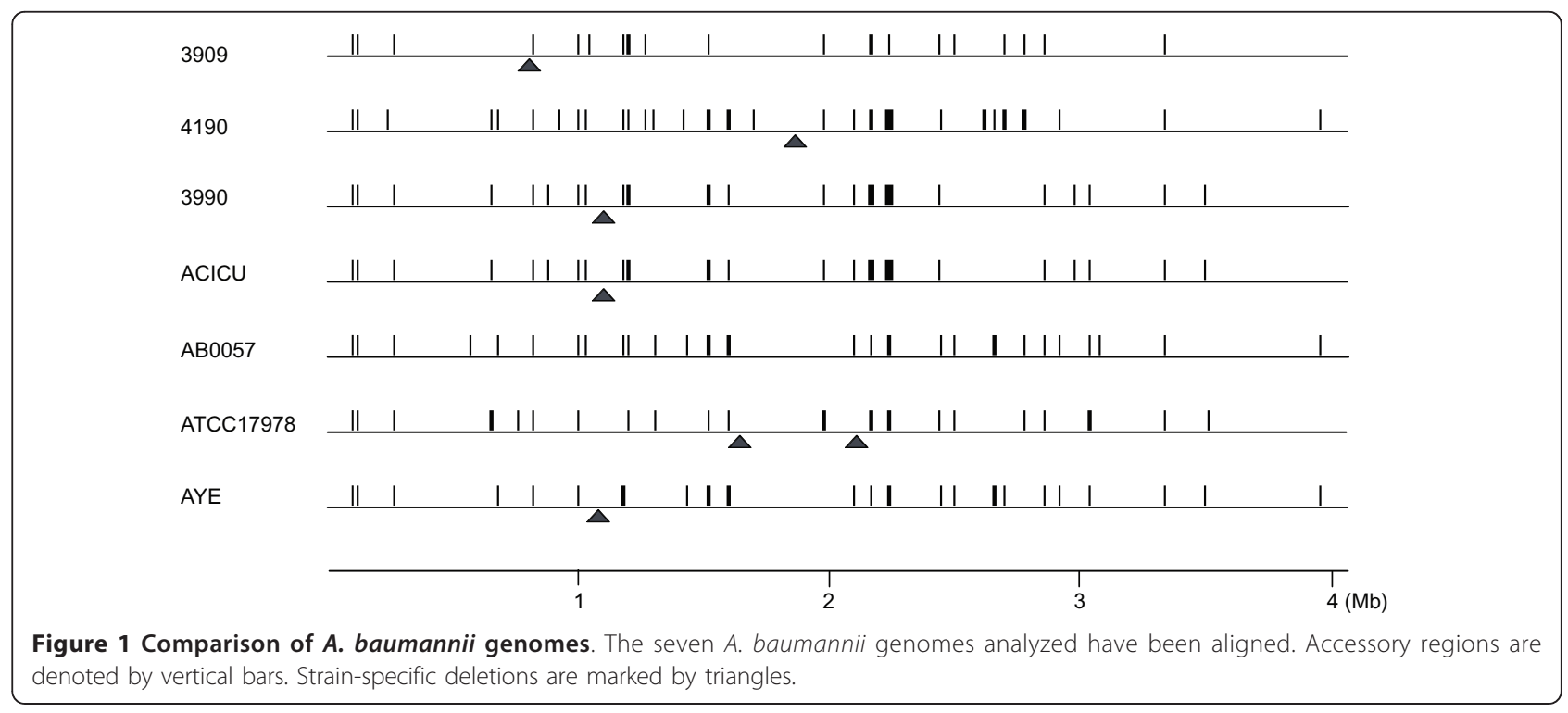


the contigs and the GEI DNA content of the corresponding chromosomal regions were assessed by sequencing PCR products bridging contigs ends.

A close look at A. baumannii chromosomes further identified about one hundred DNA regions encoding 12 ORFs smaller than $4 \mathrm{~kb}$ conserved in one or more strains, but missing, or replaced by non homologous DNA of comparable length, in others. The potential gene products encoded by these smaller accessory regions, that we called mhrs (for micro-heterogeneity regions), are reported in Additional file 5.

\section{Categories of genomic islands}

Some islands are strain-specific; others are completely or partially conserved in more than one strain. Non homologous islands are inserted at the same locus in different strains, and some loci are extremely heterogeneous, featuring up to 4-5 alternative islands. Some islands are composite, and changes in their organization among strains are correlated to changes in the number and association of specific DNA segment. Thus, for example, G54 $4_{\text {ST78 }}$ can be viewed as made by ABC segments. Segments $A B$ are missing in $G 54_{\mathrm{acb}}$, segments $\mathrm{AC}$ in both G54 $4_{\text {abn }}$ and G54 $4_{\text {aby }}$, and segment C is replaced by a shorter DNA segment in G54 acb (see Additional file 4 for a direct G54 islands comparison). On the basis of the putative gene products, GEIs can be broadly sorted into a few categories. Properties and overall organization of relevant GEIs are below discussed.

\section{Resistance islands}

Many of the accessory drug resistance determinants of Table 2 found in AB0057 and AYE are encoded by genes located within $\mathrm{G}_{\mathrm{aby}}$, $\mathrm{G} 4_{\mathrm{abn}}$ and $\mathrm{G} 5_{\mathrm{abn}}$, which correspond to the resistance regions previously described as AbaR1, AbaR3, and AbaR4 [16,30], respectively. G4 aby and $\mathrm{G} 4_{\mathrm{abn}}$ are both inserted in the comM gene, and result from the association of the $16 \mathrm{~kb}$ Tn6019 transposon with multiple antibiotic resistance regions (MARR), which are delimited by Tn6018 elements [30]. Tn6019 features genes involved in transposition (tniA, tniB), an arsenate resistance operon, a universal stress protein gene (uspA), and a sulphate permease gene (sup). MARR are inserted within uspA and vary in length and composition [30]. The $\mathrm{G}_{\mathrm{abc}}$ island of the $\mathrm{ACICU}$ genome corresponds to the AbaR2 region [30], which carries few resistance genes and lacks Tn6019 sequences (Figure 3A). G4 $4_{\mathrm{ST} 78}$ is similarly inserted in the $\operatorname{comM}$ gene, and features genes homologous to tniA and $t n i B$ (38-40\% identity of the gene products), but lacks resistance genes and encodes a set of hypothetical proteins (Figure 3A). G4 is missing in strain 4190. However, resistance genes are scattered in different GEIs of this strain (Figure 3B). The aadA1 (streptomycin 3"- adenylyltransferase) gene, flanked by sat $R$ (streptothricin acetyltransferase) and $d h f r$ (dihydrofolate reductase) genes are found in $\mathrm{G}_{63} 3_{\mathrm{ST} 25}$. Genes involved in resistance to mercury (merRCAD cluster) are located in $\mathrm{G}_{\mathrm{ST} 25}$, and a $4.5 \mathrm{~kb}$ DNA segment containing feo $\mathrm{AB}$ (ferrous iron transport operon), $c z c$ (tricomponent proton/cation antiporter efflux system) and ars (arsenite transporters) genes are found in $\mathrm{G}_{\mathrm{ST} 25}$, next to the cus (copper resistance) genes conserved in all G8 (Figure 3B). The G62 $2_{\text {acb }}$ region also contains cus, feo and $c z c$ genes involved in heavy metal resistance. These genes differ in sequence and overall arrangement from $\mathrm{G}_{\mathrm{ST} 25}$ homologs. This supports the notion that the set of accessory genes had been independently acquired by the strains 4190 and ATCC17978.

Additional resistance genes found in GEIs include an aminoglycoside phosphotransferase gene $\left(\mathrm{G} 41_{\mathrm{ST} 25}\right.$, $\left.\mathrm{G} 41_{\mathrm{abc}}\right)$, a dihydropteroate synthase gene ( $\left.\mathrm{G} 9_{\mathrm{acb}}\right)$, and an ABC-type multidrug transport system, conserved in all the G32 islands.

\section{GEls encoding surface components and transport systems}

GEI-1 and GEI-60 host genes involved in cell envelope. Heterogeneity among A. baumannii strains at the level of $\mathrm{O}$-antigen biosynthetic genes was already noticed (16), and is correlated to the presence of alternative glycosylases. The G44 island, present in all strains but ACICU, 3990 and 4190, is a four gene operon involved in the assembly of fimbriae (type I pili) by the chaperone/usher pathway [31]. G44 aby corresponds to the surface adhesion protein region annotated as Cus1R in the AYE genome [18]. G19 $_{\text {ST25 }}$ and $\mathrm{G} 19_{\text {ST78 }}$ are related islands which both carry an operon encoding three hypothetical lipoproteins. Of these, one exhibits homology to CsgG, the key factor in the secretion of curli, the proteinaceous component having a role in host cell adhesion and biofilm formation in many Enterobacteriaceae [32]. Purified CsgG forms ring-shaped complexes analogous to those formed by outer membrane channelforming proteins [32]. The CsgG-like protein, in association with the two co-expressed lipoproteins, may influence the permeability of the outer membrane of $A$. baumannii.

Filamentous haemagglutinin (FHA) is a major virulence factor in Bordetella pertussis [33]. fhaB and fhaC genes, respectively encoding the haemagglutinin and the transporter protein, have been identified in many pathogens [34]. fhaBC gene clusters are found at the same loci in strains 4190 and 3909 (islands G26 ${ }_{\text {ST25 }}$, G26 $_{\text {ST78, }}$, G49 ST25 $_{\text {ST }}$ and $49_{\text {ST78 }}$ ), and strains ACICU and 3990 (islands $\mathrm{G} 38_{\mathrm{abc}}$ and $\mathrm{G} 38_{\mathrm{ST} 2}$ ). The transporter proteins are highly conserved in the four clusters, whereas FHAs vary in length (1834 to 4812 amino acids), mostly because of changes in the number and organization of 


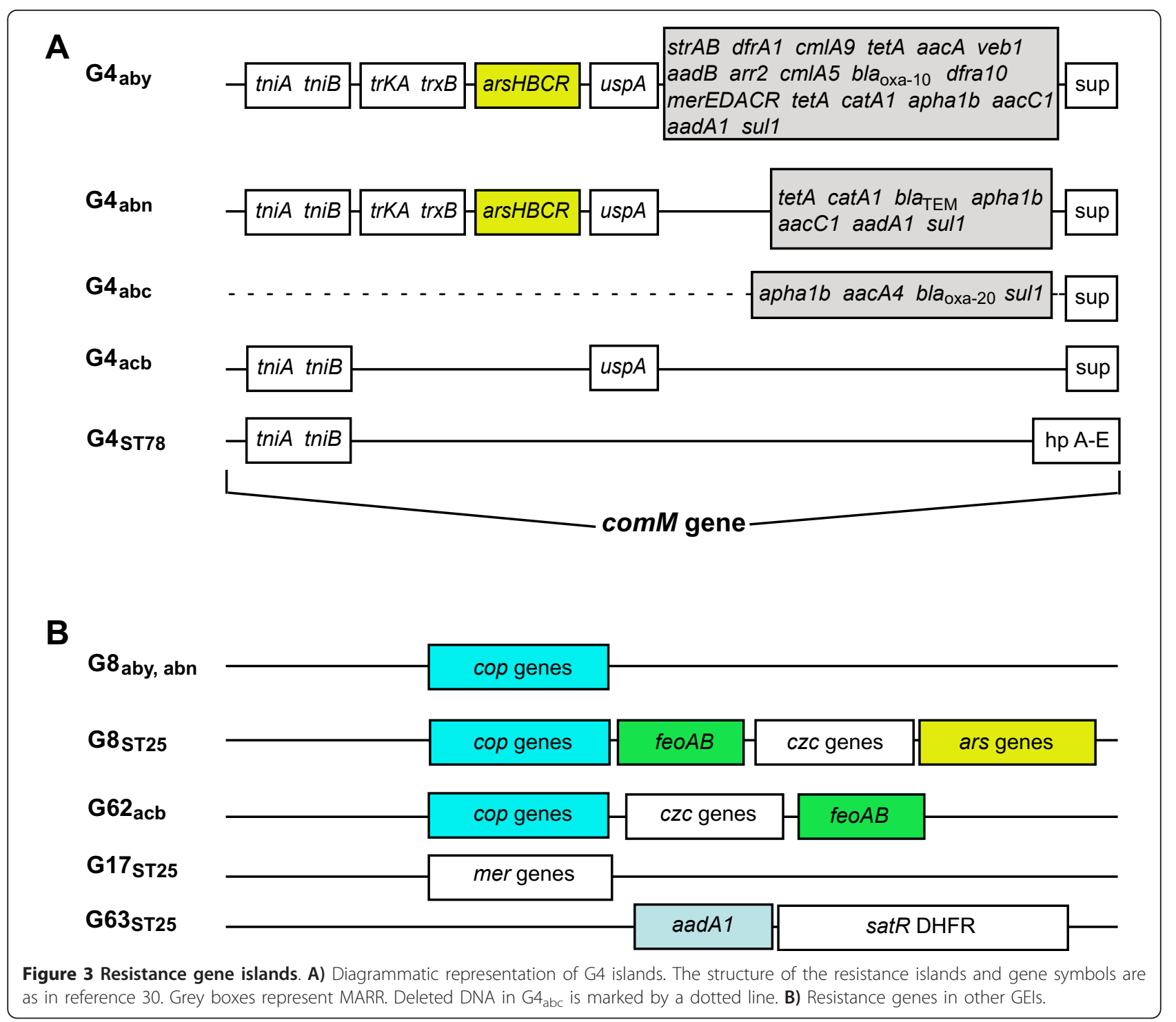

body sequence repeats [33]. A 3216 amino acids long calcium binding hemolysin protein, unrelated to FHAs, is encoded by $\mathrm{G} 18_{\text {acb }}$.

Cyclopropane fatty acids (CFA) are phospholipids found in the bacterial membranes in the late exponential and early stationary phases of cell growth [35], which derive from the corresponding unsaturated fatty acid (UFA) phospholipids. The synthesis of CFA is catalyzed by the enzyme CFA synthase, the substitution of a saturated by an unsaturated fatty acid by the enzyme delta-9 acyl-lipid desaturase. CFA synthase and delta- 9 acyl-lipid desaturase are both encoded by $\mathrm{G}_{47} 7_{\mathrm{abn}}$ and G47 $7_{\text {aby. }}$.

G33 ST25 $_{\text {is a large island which encodes four different }}$ transport and translocation systems: i) Tat (twin-arginine translocation) proteins, involved in the translocation of folded proteins to the cell envelope or the extracellular space ii) a TonB/ExbBD complex iii) a Opp (oligopeptide transport proteins) complex iv) a sulfur utilization system, made by a FMNH2-dependent sulfonatase and three $\mathrm{ABC}$-type transporters, which resemble the products of the E. coli ssu gene cluster [36]. Two unlinked copies of the sulfonatase gene are also present. Genes involved in the capture and intracellular transport of iron are found in different islands. G57 abc carries a gene cluster involved in the synthesis of the high-affinity siderophore enterobactin. Heme oxygenase is an alternative to siderophores to capture iron from the environment [37]. G14, an island which is conserved in 4190, ACICU and AB0057, carries an operon encoding a heme oxygenase, an outer membrane and a TonB family protein. The presence of a flanking fecIR gene cluster suggests that heme internalization may be regulated by the Fec transduction system [38]. The fhuBCD genes, 
which catalyze the internalization of iron III hydroxamate compounds, are located on G36, an island conserve in all strains but AB0057 and AYE.

\section{Metabolic islands}

Many GEIs carry genes encoding proteins involved in specific metabolic pathways. G23 $3_{\mathrm{ST} 25}$ carries a $\mathrm{mph}$ (multi component phenol hydroxylase) gene complex, involved in the conversion of phenol to cathecol, flanked by a sigma54-dependent activator gene. It has been shown that the expression of $m p h$ gene complex described in Acinetobacter sp. PHAE-2 is dependent on the alternative sigma factor RpoN [39]. G37 ST25 $_{\text {carries }}$ nag genes, involved in the metabolism of naphthalene. In Ralstonia [40], nag genes are arranged in two separate clusters, involved in the conversion of naphthalene to gentisate (nagAGHBFCQED genes), and gentisate to pyruvate and fumarate (nagIKL genes), respectively. In G37 ${ }_{\text {ST25 }}$ nagIKL genes and nagGH, encoding the salicylate 5-hydroxylase, are linked, and flanked by benzoate transport genes.

G43 $3_{\text {ST25 }}$ carries genes involved in the catabolism of 3HPP (3-hydroxyphenylpropionic acid) and PP (phenylpropionic acid). In $E$. coli, the dioxygenase complex (hcaEFCD genes), and the dihydrodiol dehydrogenase (hcaB gene) oxidize PP (phenylpropionic acid) and CI (cinnamic acid) to DHPP (2,3-dihydroxyphenylpropionate) and DHCI (2,3-dihydroxycinnamic acid), respectively. These substrates are subsequently converted to citric acid cycle intermediates by the $m h p$ genes products [41]. The hca and $m h p$ genes, separated in E. coli, are linked and interspersed with additional genes (see Additional file 4) in $\mathrm{G} 43_{\mathrm{ST} 25}$. G21 $1_{\mathrm{ST} 25}$ potentially encodes 4 proteins (tartrate dehydratase subunits alpha and beta, a MFS transporter and a transcriptional regulator) possibly involved in the metabolism of tartrate. Proteins exhibiting homology to the dienelactone hydrolase, an enzyme which plays a crucial role in the degradation of chloro-aromatic compounds, are encoded by the islands $\mathrm{G}^{3} 0_{\text {ST25 }}, \mathrm{G} 34_{\mathrm{abn}}$ and G34 $4_{\mathrm{aby}}$. G46 $6_{\mathrm{ST} 25}$ is made by an operon including the salicylate 1-monooxygenase (salA), a benzoate transporter (benK) and the salA regulator (salR) genes. A salicylate 1-monooxygen-

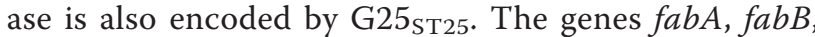
$f a \mathrm{~b} G, f a b F, a c p P, p s l B, a c s A$, involved in the biosynthesis of fatty acids [35] are conserved in all A. baumannii strains, at separate loci. Orthologues of all these genes are clustered in $\mathrm{G6}_{\mathrm{abc}}$ and $\mathrm{G6}_{\mathrm{acb}}$.

\section{Phage islands}

Many variable genomic regions are relatively large (19 to $82 \mathrm{~kb})$ DNA blocks which potentially encode typical phage products. These regions have all been classified as cryptic prophages (CP; see Figure 2). Three to six CPs were identified in each strain. Six of the different 14 CPs identified are present in two or more strains, the remaining 8 are strain-specific. CPs characteristically carries at one end an integrase gene, and many are sharply defined by flanking TSDs induced upon insertion. CPs are poorly related to each other, and even CPs of the same type differ in size and coding ability. Ten of 14 CPs were assigned to four groups on the basis of sequence homologies (Additional file 6). CPs found at the same locus encode identical or highly homologous (> $80 \%$ identity) integrases. CP1 encode different integrases, which are homologous to CP5- or CP9-encoded enzymes. This explains why CP1 and CP5 in AB0057 and ATCC17978 (G22 $2_{\mathrm{abn}}$ and $\mathrm{G} 22_{\mathrm{acb}}$, respectively), and CP1 in 3909 and ACICU (G42 $2_{\text {ST78 }}$ and G42 $2_{\mathrm{abc}}$ ), and CP9 in ATCC 17978 (G42 2 acb), are inserted at the same locus. CP3 are integrated at different sites of the AB0057 genome (G52 abn and G59 $\left.9_{\mathrm{abn}}\right)$, but the target in both is an $\arg -t R N A$ gene.

Remnants of prophage sequences are found in $\mathrm{G} 33_{\mathrm{abn}}$ and $\mathrm{G} 33_{\text {aby }}$. These islands share the $\mathrm{G} 33_{\mathrm{abc}}$ backbone, but contain also large DNA segments, reiterated in a head-to-tail configuration, in which genes encoding phage and hypothetical proteins are variously interleaved. G33 ${ }_{\mathrm{abn}}$ and $\mathrm{G} 33_{\mathrm{aby}}$ hypothetical gene products exhibit poor homology to all CPs gene products, and therefore were not included among CPs.

Phages may acquire ORFs named morons [42] by lateral gene transfer. The PapS reductase (3'-phosphoadenosine 5'-phosphosulfate sulfotransferase) encoded by CP13 (G56 abc), the toxin-antitoxin (TA) system encoded by CP1 (G42 $2_{\mathrm{abc}}$ and $\left.\mathrm{G} 42_{\mathrm{ST} 78}\right)$, the proofreading $3^{\prime}-5^{\prime}$ exonuclease epsilon subunit of the DNA polymerase III in the above mentioned CPs, the $u m u D C$ gene products, which are the components of the error-prone DNA polymerase $\mathrm{V}$, again in $\mathrm{CP} 1\left(\mathrm{G} 22_{\mathrm{abn}}\right.$ and $\left.\mathrm{G} 42_{\mathrm{ST} 78}\right)$ and CP5 $\left(\mathrm{G} 22_{\mathrm{abc}}\right)$ can all be considered morons. Not surprisingly, these enzymes are frequently associated with mobile genome elements [43]. Unlinked $u m u D$ and umu $C$ genes are conserved in all A. baumannii strains, and an $u m u D C$ cluster resides on the $64 \mathrm{~Kb}$ pACICU2 plasmid.

G9 $9_{\text {acb }}$ also contains an $u m u D C$ cluster. This $126 \mathrm{~kb}$ region, found only in the ATCC 17978 strain, is a composite genomic island, carrying at one end a dihydropteroate synthase gene, at the other a DNA mismatch repair enzyme. G9 $9_{\text {acb }}$ carries a complete set of type IV secretion system (T4SS) genes, arranged in the same order in which T4SS homologs are found on the $153 \mathrm{~Kb}$ plasmid of Yersinia pseudotuberculosis IP31758 strain [44]. Because $u m u D C$ genes are carried by this plasmid, one may hypothesize that raises $G 9_{\text {acb }}$ had been imported from Yersinia. In addition, a G9 acb gene cluster, including an integrase, a DNA helicase and a TrbL/ 
VirB6 conjugal transfer protein is highly homologous to a gene cluster from Enterobacter cloacae.

\section{Additional islands}

$\mathrm{G}_{\text {ST25 }}$ carries a cre genes cluster. In $E$. coli the cre locus includes a response regulator $(\mathrm{cre} B)$ a sensor kinase $(\mathrm{cre} C)$ and an inner membrane protein ( $\mathrm{creD})$. The corresponding two-component regulatory system $\mathrm{CreB}$ $\mathrm{CreC}$ controls the expression of a variety of genes, among which the $c r e D$ regulator. Overexpression of CreBC causes modification of the envelope, inducing the colicin E2 tolerance phenotype [45].

G51 $1_{\mathrm{ST25}}$ and $\mathrm{G} 51_{\mathrm{acb}}$ carry the $r t c A$ and $r n t \mathrm{Z}$ genes, encoding the RNA 3'-terminal phosphate cyclase and the RNAseZ, respectively. The cyclase catalyzes the ATP-dependent conversion of the 3'-phosphate to the 2', 3'-cyclic phosphodiester at the end of various RNA substrates [46]; RNAseZ is responsible for the maturation of the 3'-end of a large family of transfer RNAs [47]. In $E$. coli the 3'-terminal phosphate cyclase $r t c A$ gene forms an operon with the upstream $r t c B$ gene. Expression of $r t c A B$ is regulated by $r t c R$, a gene positioned upstream of $r t c A B$, but transcribed in the opposite direction, encoding a sigma54-dependent regulator [46]. $r t c B A$ and $r t c R$ genes are conserved in both $\mathrm{G} 1_{\mathrm{ST} 25}$ and $\mathrm{G} 51_{\text {acb }}$ islands, separated by $r n t Z$. Interestingly, only $r n t Z$ is present at the corresponding chromosomal position in strains lacking G51.

In type I restriction systems the three subunits $\mathrm{S}, \mathrm{M}$ and $\mathrm{R}$, which may variably associate to form a modification methylase or a restriction endonuclease, are encoded by hsd (host specificity of DNA) genes. Alternative $h s d$ genes reside in $\mathrm{G}_{13} 3_{\mathrm{ST} 25}$ and $\mathrm{G} 13_{\mathrm{ST} 78}$. The former are clustered in one operon, whereas $h s d S M$ and $h s d R$ genes in $\mathrm{G} 13_{\mathrm{ST} 78}$ are at distance, as frequently found in other species.

Homologs of a cytosine DNA methyltransferase and a restriction endonuclease, which may constitute a type II restriction modification system, are encoded by genes residing in $\mathrm{G} 38_{\text {ST78 }}$.

The G55 islands found in strains 4190, AB0057 and AYE are closely related, and all include a CRISPR (Clustered Regularly Interspaced Short Palindromic Repeats) block, flanked by a cas (CRISPR-associated) gene cluster. CRISPRs are repeated DNA sequence blocks found in the genomes of approximately $40 \%$ of bacteria, often next to a cluster of cas genes. The CRISPR/Cas system provides a form of acquired immunity against exogenous DNA, foreign DNA sequences being first integrated at the CRISPR locus and eventually degraded by Cas proteins [48]. Horizontal transfer of CRISPRs and associated genes among prokaryotes is documented [49].

Gram-negative bacteria contain a variety of genes encoding proteins enriched in dipeptide motifs (valine- glycine repeats) hence called Vgr. Islands encoding Vgrlike proteins are found inserted at eight genome variable loci (loci 2, 7, 15, 17, 19, 25, 27 of Figure 2). Vgr proteins are associated with ligand-binding proteins at the bacterial surface [50], and are involved in biofilm formation and swarming and swimming motility in Burholderia [51]. Intriguingly, Vgr proteins, along with Hcp (hemolysin co-regulated) proteins, are components of the type VI (T6SS) secretion apparatus, a transport system extensively conserved among Gram-negative bacteria [52]. Secreted Vgr proteins assemble a cellpuncturing device analogous to phage tail spikes to deliver effector proteins, and are also able to covalently cross-link host cell actin contributing to T6SS pathogenicity [53]. A T6SS gene cluster is conserved in all the analyzed $A$. baumannii strains.

\section{A. baumannii GEls in other species of the Acinetobacter genus}

Acinetobacter baylyi is a non-pathogenic nutritionally versatile soil bacterium. The chromosome of the A. baylyi strain ADP1 carries metabolic genes involved in the utilization of a large variety of compounds. Most of these genes are clustered in five major catabolic islands, grouped in the so called archipelago of catabolic diversity [27]. The organization of the A. baylyi and A. baumannii chromosomes is different, and most catabolic islands of $A$. baylyi are conserved in all A. baumannii strains, although ungrouped, at separate loci (Figure 4). Interestingly, some archipelago genes were found in G33 ${ }_{\text {ST25 }}$ and $\mathrm{G}_{4} 6_{\mathrm{ST} 25}$, two accessory DNA regions specific of the A. baumannii strain 4190. Prompted by this finding, we checked whether twenty GEIs, including G33 ${ }_{\text {ST25 }}$ and $\mathrm{G}_{4} 6_{\mathrm{ST} 25}$, were present in A. baylyi (GenBank: NC_005966), in the complete genome of the diesel-degrading Acinetobacter sp. strain DR1 (GenBank: NC_014259) [54] and in the nine draft genomes of the Acinetobacter genus deposited at Genbank. GEIs encoding filamentous haemagglutin and vgr-proteins, as those corresponding to cryptic prophages were not searched because of their heterogeneity. The results of the survey are summarized in Table 3. Seven islands (GEIs 14, 20, $21,23,29,44,51)$ are conserved in one or more genomes, flanked at one or both sides by the same genes found in A. baumannii, but their dimensions vary, as consequence of gain/loss of DNA segments. As expected for mobile DNA, some islands were missing, and only flanking genes could be identified (genomic empty sites). Segments of $\mathrm{G} 13_{\mathrm{ST} 25}$ and $\mathrm{G} 43_{\mathrm{ST} 25}$ are spread among non-baumannii Acinetobacter genomes, thus suggesting that both GEIs might result from multiple recombination events. Recombination likely contributed to the formation of the large DR1 island encompassing genes found in $\mathrm{G} 37_{\mathrm{ST} 25}$ and $\mathrm{G} 37_{\mathrm{abc}}$, two non- 


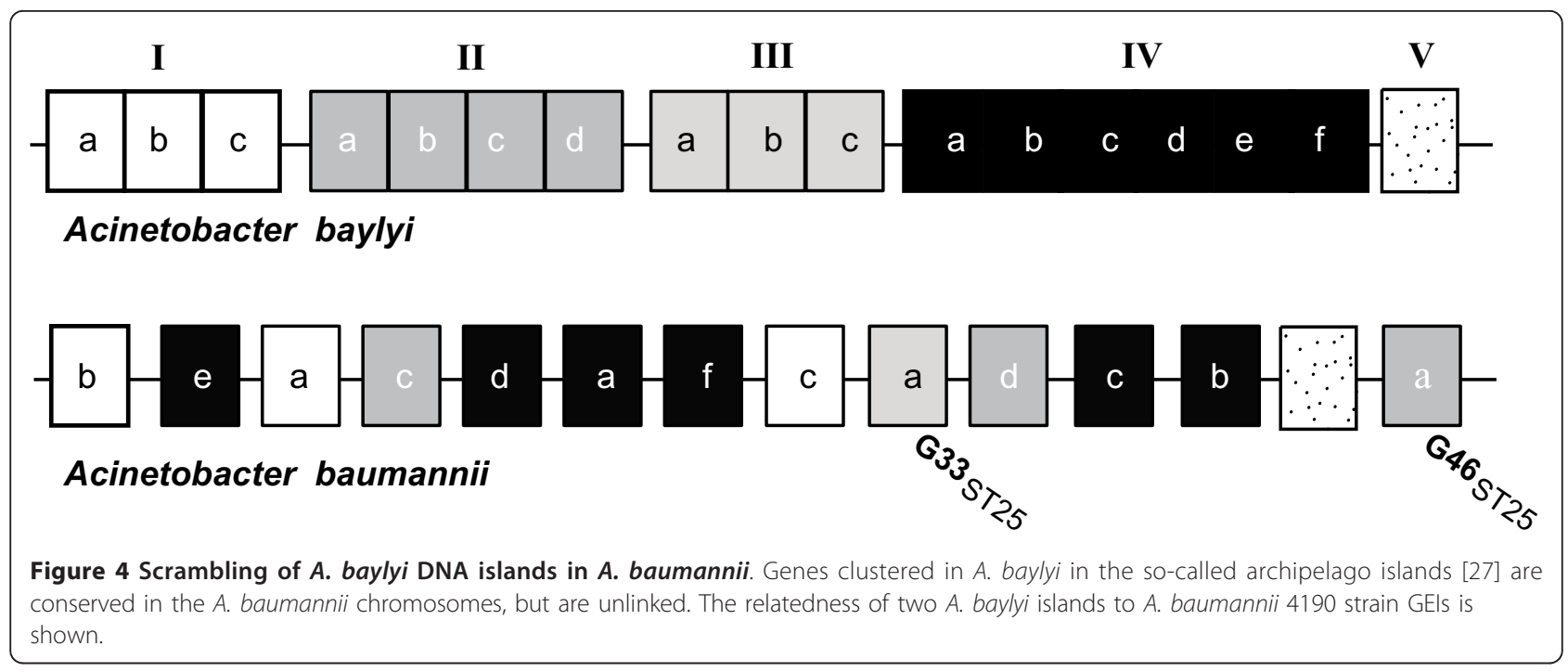

homologous GEIs encoding enzymes involved in naphthalene degradation and a RTX-type toxin. Curiously, the two $A$. baumannii islands are separated in the DR1 island by $10 \mathrm{~kb}$ DNA homologous to fhaBC genes found in $\mathrm{G} 38_{\mathrm{abc}}$.

A high number of GEIs is conserved in the genome of the Acinetobacter sp. strain DR1. Interestingly, dot plot analyses showed that gene order is more similar between A. baumannii AB0057 strain and Acinetobacter sp. strain DR1 than between the same $A$. baumannii strain and $A$. baylyi (Figure 5). According to rpoB sequence analysis, DR-1 strain belongs to the $A$. calcoaceticus-A. baumannii complex, and is closely related (99.7\% identity) to gen. sp. "Between 1 and 3" [3].

\section{Genomic regions in A. baumannii strains of different genotypes}

The distribution of 18 genomic islands in the A. baumannii population was monitored by PCR analyses. Coding DNA regions of 600-1500 bp, representative of each GEI, were amplified from the DNA of $23 \mathrm{~A}$. baumannii strains associated with 21 epidemics that occurred in 14 hospitals of the Mediterranean area from 1999 to 2009, including the sequenced 3909 and 4190 strains used as control. Nearly all the strains were representative of cross-transmission episodes, and were isolated with identical PFGE types from more than two patients of the same or different institutions [9]. Strains belong to eight different STs, and 10/23 strains are ST2. PCR data are summarized in Table 4. Taking into account that negative data may denote partial island deletion or polymorphism in sequences targeted by the primers, the conservation of islands seems to vary significantly among the analyzed strains. G43 and G51 had been found in most strains but not in the two strains assigned to ST78 and some strains assigned to ST2. In contrast, G18 is missing in all except one ST25 strain (4190), and G57 is found only in 3 strains of different STs. G47 seems to be a marker of ST1 strains, being found in all 5 strains assigned to ST1, as well in two strains assigned to ST20, which is a single locus variant of ST1. Similarly, G6 and G11 seem to be markers of ST2 strains, being found in all 10 ST2 strains. Interestingly, the three islands are also present in the single ST3 strain analyzed. G37 is also found in all ST2 strains and also in strains assigned to ST3, ST15 and ST84. G32 is found in all but not ST1 and ST20 strains. All the eleven islands found in the genome of the 4190 strain are conserved in the other two ST25 strains analyzed, with the exception of G8 and G63, both missing in the 3890 strain. Of the eleven islands, two (G23 and G46) are found only in the 3 ST25 strains, six (G3, G8, G63, G43, G21, G51) are also present in strains assigned to other STs. No correlation was found between the pattern of island distribution and PFGE profile among strains.

\section{Discussion}

Data reported are in line with the results of previous analyses [16], indicating that the genomes of $A$. baumannii strains isolated from geographically different regions are closely related and share the same overall organization. Shared synteny made possible to align the seven A. baumannii genomes throughout, and obtain a robust chromosomal scaffold by which easily distinguish core and accessory genome components in each strain.

The ST2 strains ACICU and 3990 exhibit 99.9\% sequence identity, and share the same core and variable genome components. Mapped differences are restricted to size changes of 40 intergenic regions, which vary in 
Table 3 Distribution of genomic regions in non-baumannii Acinetobacter species

\begin{tabular}{|c|c|c|c|c|c|c|c|c|c|c|c|c|}
\hline $\begin{array}{l}\text { A. } \\
\text { baumannii } \\
\text { GEls }\end{array}$ & $\begin{array}{l}\text { ORF } \\
\text { contained }\end{array}$ & $\begin{array}{l}\text { A.baylyi } \\
\text { ADP1 }\end{array}$ & $\begin{array}{l}\text { A.calcoaceticus } \\
\text { RUH2202 }\end{array}$ & $\begin{array}{l}\text { A. haemolyticus } \\
\text { ATCC19194 }\end{array}$ & $\begin{array}{l}\text { A. johnsonii } \\
\text { SH046 }\end{array}$ & $\begin{array}{l}\text { A. junii } \\
\text { SH205 }\end{array}$ & $\begin{array}{l}\text { A. Iwoffii } \\
\text { SH145 }\end{array}$ & $\begin{array}{l}A . \\
\text { radioresistens } \\
\text { SK82 }\end{array}$ & $\begin{array}{l}\text { Acinetobacter sp. } \\
\text { ATCC27244 }\end{array}$ & $\begin{array}{l}\text { Acinetobacter } \\
\text { sp. DR1 }\end{array}$ & $\begin{array}{l}\text { A. nosocomialis } \\
\text { RUH2624 }\end{array}$ & $\begin{array}{l}\text { A. pittii } \\
\text { SH024 }\end{array}$ \\
\hline G13 (ST25) & [A to $L]$ & - & $C$ & $\mathrm{HL}$ & $\mathrm{HL}$ & $A B$ & $\mathrm{HL}$ & - & EFG...HL & C & $C$ & CDE HL \\
\hline G14 & [A to $\mathrm{H}]$ & {$[\mathrm{A}$ to $\mathrm{H}]$} & [A to $\mathrm{H}]$ & - & - & - & - & - & [A to $\mathrm{H}]$ & [A to $\mathrm{H}]$ & [ ] & [A to $\mathrm{H}]$ \\
\hline G18 (ST78) & {$[A B]$} & - & - & - & - & - & - & - & - & {$[A B$} & - & {$[\mathrm{AB}$} \\
\hline G20 (ST78) & [A to $C$ ] & [ ] & - & $B C$ & - & - & - & - & [ ] & [A to $C$ ] & [ ] & [A to $C$ ] \\
\hline G21 (ST25) & [A to $E]$ & - & [ ] & - & - & - & - & - & - & [A to $E]$ & [ ] & [A to $E]$ \\
\hline G23 (ST25) & [A to $\mathrm{H}]$ & - & [ ] & - & - & - & - & A to $G$ & - & [A to $\mathrm{H}]$ & [A to $\mathrm{H}]$ & [A to $\mathrm{H}]$ \\
\hline G29 (ST25) & {$[A$ to $D]$} & - & - & - & - & - & - & - & - & [A to $D]$ & [A to $D]$ & [ ] \\
\hline G33 (ST25) & [A to $\mathrm{AF}]$ & $\begin{array}{l}\text { [A to } \\
\mathrm{AF}]^{\#}\end{array}$ & - & - & - & - & - & - & - & {$[\mathrm{A} \text { to } \mathrm{AF}]^{\#}$} & - & - \\
\hline G35 (abc) & {$[\mathrm{A}$ to $\mathrm{N}]$} & - & - & - & - & - & - & - & - & [novel GEI] & - & $C, N$ \\
\hline G36 & [A to I] & - & {$[\mathrm{A} \text { to } \mathrm{I}]^{\#}$} & - & - & - & - & - & - & [A to I] $]^{\#}$ & [A to $F$ & [C to $\mathrm{F}$ \\
\hline G37 (ST25) & [A to $\mathrm{H}]$ & - & - & $B$ to $E$ & - & - & - & - & - & {$[\mathrm{A} \text { to } \mathrm{H}]^{\#}$} & [ ] & [ ] \\
\hline G37 (abc) & [A to $G]$ & - & - & - & - & - & - & - & - & {$[A \text { to } G]^{\#}$} & [ ] & [A to $G]^{\#}$ \\
\hline G43 (ST25) & {$[\mathrm{A}$ to $\mathrm{V}]$} & - & - & - & - & - & FG...H to $V$ & FG...H to $V$ & - & - & A to $C$ & - \\
\hline G44 & [A to $D]$ & - & {$[A$ to $D]$} & - & - & - & - & - & - & [A to $D$ & $A$ to $D$ & [A to $D]$ \\
\hline G46 (ST25) & [A to $E]$ & $\mathrm{CDE}$ & $\mathrm{CDE}$ & - & - & - & - & - & - & CDE & [ ] & [ ] \\
\hline $\begin{array}{l}\text { G47 (abn, } \\
\text { aby) }\end{array}$ & [A to $R]$ & $\mathrm{BL}$ & - & L & - & $\mathrm{BL}$ & - & - & - & [B to $R$ ] & [B to $R$ ] & [B to $\mathrm{R}$ ] \\
\hline G51 (abc) & [A to $G]$ & - & [A to $G]$ & [A to $G]$ & - & [A to $\mathrm{G}]$ & - & - & $B$ to $L$ & [A to $G$ ] & $C$ & [A to $G]$ \\
\hline G57 (acb) & [A to $\mathrm{H}]$ & $M$ to $A G$ & & - & - & [ ] & - & - & - & [ ] & [ ] & - \\
\hline
\end{tabular}

ORFs in each island are referred to by capital letters. Brackets denote ORFs flanking genomic islands. Conserved genomic regions are highlighted in bold. Dots between letters denote that corresponding ORFs are not contiguous. \#Genomic regions larger than those identified in A. baumannii. 


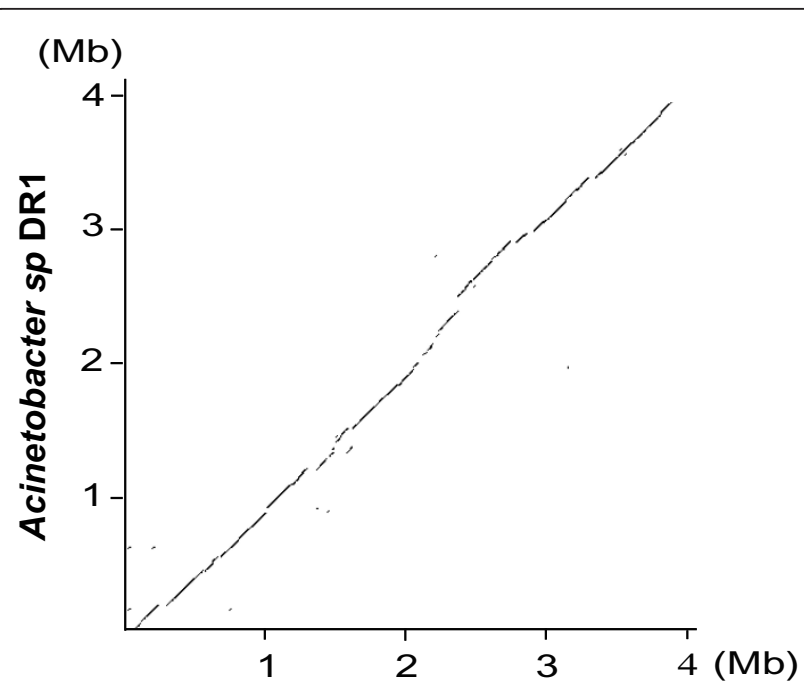

Acinetobacter baumannii AB0057

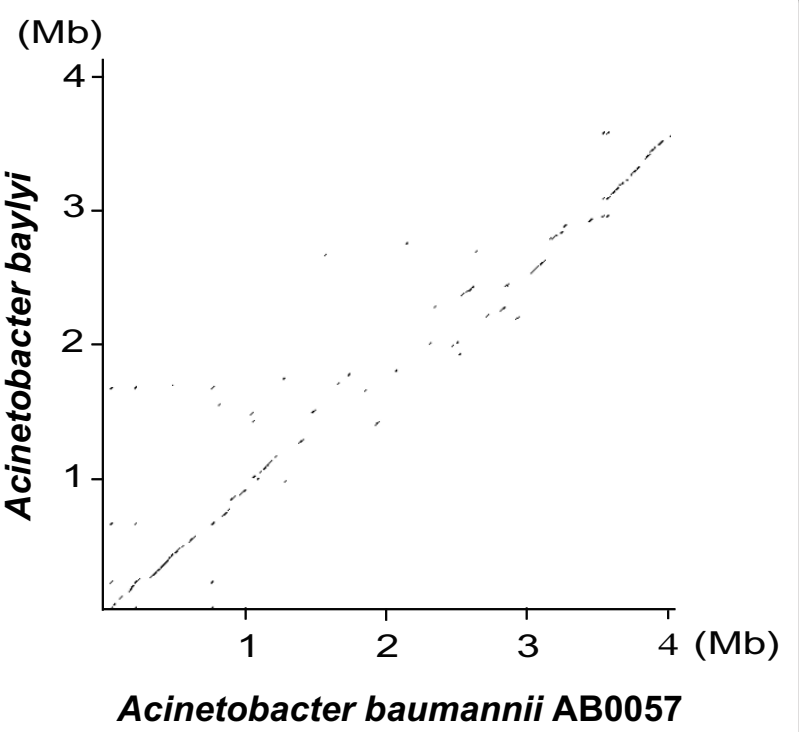

Figure 5 Dot plot comparisons of Acinetobacter genomes. The degree of relatedness of the A. baylyi and Acinetobacter $s p$. DR1 chromosomes to the A. baumannii AB0057 chromosome is illustrated by dot plot comparisons.

the two strains because they contain a different number of short sequence repeats. A major difference can be ascribed to a $>36 \mathrm{~kb}$ CP3-like element, found in the 3990 strain only, the chromosomal location of which has not yet been determined. Two CP3-like prophages specific of strains 3909 and 4190 have not yet been mapped as well. The ACICU and 3990 strains are however phenotypically distinguishable, since the his-leu replacement at residue 535 of the beta subunit of the RNA polymerase made the 3990 strain not susceptible to rifampicin (MIC > $500 \mathrm{mg} / \mathrm{L}$ ). Sequence comparisons revealed that 3068 coding regions are conserved, at the same chromosomal position, in all A. baumannii genomes. Accessory coding regions, including both GEIand mhr-encoded ORFs, varies from 433 (3909 strain) to 707 (AB0057 strain). In estimating the number of conserved coding regions, it was taken into account that many correspond to a single ORF in one genome, but to two or even three adjacent ORFs in others, and vice versa. Likely most "double ORFs" are artifactual, since mutations are known to be introduced by PCR amplification of DNA samples prior to sequencing. Accessory DNA regions correspond to $12 \%$ of the 3909 genome, $19 \%$ of the AB0057 genome, and to $14-16 \%$ of all other genomes analysed. Although closure of draft genomes and addition of whole genome sequences of other strains may lead to the definition of a few additional GEIs, data clearly indicate that $A$. baumannii strains exhibit less variation than $E$. coli strains, which may share only $60-70 \%$ of their coding capacity [55].

Many A. baumannii GEIs have a role in drug resistance, biosynthesis of surface components, iron metabolism, and this may confer advantage in the course of an infection, since successful pathogens encode multiple adhesins, are equipped to sequester iron from the environment and can escape therapy. Less clear is the advantage conferred to A. baumannii by other islands. The functional role of the RNA 3'-terminal phosphate cyclase, an enzyme conserved among Bacteria, Archaea and Eucarya, encoded by $\mathrm{G} 51_{\mathrm{ST} 25}$ and G51 $1_{\text {acb }}$, is debated. The same holds for vgr-like proteins, encoded by several GEIs, though it is worth noting that six of the ten genomic islands identified in the pathogenic $P$. aeruginosa PA01 strain [56] encode vgr-like proteins. Some GEIs carry genes involved in lipid metabolism. G47 abn and G47 aby carry genes controlling the formation of CFA and UFA phospholipids. Cyclopropanation plays a role in the pathogenesis of Mycobacterium tuberculosis, a specific CFA synthase being required to modify the alpha mycolates on the cell envelope, and pathogenic E. coli strains have higher CFA contents and are more resistant to acid shock than non-pathogenic strains [57]. $\mathrm{G6}_{\mathrm{abc}}$ and $\mathrm{G6} 6_{\mathrm{acb}}$ carry homologues of genes involved in fatty acid metabolism (Fab genes) conserved at multiple loci in all A. baumannii strains. Additional Fab genes may confer metabolic advantage, and is worth noting that Fab and other GEI-6 genes reside in OI-47, a genomic island conserved in all O157:H7 E. coli strains [58]. Finally, Many GEIs, most of which unique to the 4190 strain, carry genes and/or operons controlling specific metabolic pathways, such as naphthalene and phenyl-propionic acid degradation.

Several GEIs correspond to cryptic prophages. Of these, a few may have conserved the ability to replicate 
Table 4 Distribution of genomic regions in A.baumannii strains of different genotypes

\begin{tabular}{|c|c|c|c|c|c|c|c|c|c|c|c|c|c|c|c|c|c|c|c|}
\hline Strain & ST type & PFGE type & G47 & G37 & G11 & G6 & G57 & G18 & G51 & G32 & G20 & G43 & G3 & G21 & G33 & G23 & G46 & G63 & G8 \\
\hline AB0057 & 1 & nd & 1 & 0 & 0 & 0 & 0 & 0 & 0 & 0 & 0 & 0 & 0 & 0 & 0 & 0 & 0 & 0 & 0 \\
\hline AYE & 1 & nd & 1 & 0 & 0 & 0 & 0 & 0 & 0 & 0 & 0 & 0 & 0 & 0 & 0 & 0 & 0 & 0 & 0 \\
\hline 700 & 1 & A & 1 & 0 & 0 & 0 & 0 & 0 & 1 & 0 & 0 & 1 & 1 & 1 & 0 & 0 & 0 & 1 & 0 \\
\hline 3891 & 1 & B & 1 & 0 & 0 & 0 & 0 & 0 & 1 & 0 & 0 & 1 & 1 & 1 & 0 & 0 & 0 & 1 & 1 \\
\hline 3887 & 1 & C & 1 & 0 & 0 & 0 & 0 & 0 & 1 & 0 & 0 & 1 & 1 & 1 & 1 & 0 & 1 & 1 & 0 \\
\hline 2979 & 20 & D & 1 & 0 & 0 & 0 & 0 & 0 & 1 & 0 & 0 & 1 & 1 & 0 & 0 & 0 & 0 & 1 & 0 \\
\hline 3130 & 20 & $\mathrm{E}$ & 1 & 0 & 0 & 0 & 0 & 0 & 1 & 0 & 0 & 0 & 0 & 0 & 0 & 0 & 0 & 0 & 0 \\
\hline $\mathrm{ACICU}$ & 2 & nd & 0 & 1 & 1 & 1 & 0 & 0 & 0 & 1 & 0 & 0 & 0 & 0 & 0 & 0 & 0 & 0 & 0 \\
\hline 2105 & 2 & $\mathrm{~F}$ & 0 & 1 & 1 & 1 & 0 & 0 & 1 & 1 & 0 & 1 & 0 & 0 & 0 & 0 & 0 & 1 & 1 \\
\hline 2638 & 2 & $\mathrm{~F}$ & 0 & 1 & 1 & 1 & 0 & 0 & 1 & 1 & 0 & 1 & 0 & 0 & 0 & 0 & 0 & 1 & 1 \\
\hline 3892 & 2 & $\mathrm{~F}$ & 0 & 1 & 1 & 1 & 0 & 0 & 0 & 1 & 0 & 0 & 0 & 0 & 0 & 0 & 0 & 0 & 0 \\
\hline 3990 & 2 & $F$ & 0 & 1 & 1 & 1 & 0 & 0 & 0 & 1 & 0 & 0 & 0 & 0 & 0 & 0 & 0 & 0 & 0 \\
\hline 2735 & 2 & F1 & 0 & 1 & 1 & 1 & 0 & 0 & 0 & 1 & 0 & 0 & 0 & 0 & 0 & 0 & 0 & 0 & 0 \\
\hline 3858 & 2 & F2 & 0 & 1 & 1 & 1 & 0 & 0 & 0 & 1 & 0 & 0 & 0 & 0 & 0 & 0 & 0 & 0 & 0 \\
\hline 3889 & 2 & G & 0 & 1 & 1 & 1 & 0 & 0 & 0 & 1 & 0 & 0 & 0 & 0 & 1 & 0 & 0 & 0 & 0 \\
\hline 4026 & 2 & $\mathrm{H}$ & 0 & 1 & 1 & 1 & 1 & 0 & 0 & 1 & 0 & 1 & 0 & 1 & 0 & 0 & 0 & 0 & 1 \\
\hline 4030 & 2 & I & 0 & 1 & 1 & 1 & 0 & 0 & 0 & 1 & 1 & 0 & 0 & 0 & 0 & 0 & 0 & 0 & 0 \\
\hline 4009 & 2 & J & 0 & 1 & 1 & 1 & 0 & 0 & 0 & 1 & 0 & 0 & 0 & 0 & 0 & 0 & 0 & 0 & 0 \\
\hline 4025 & 3 & K & 1 & 1 & 1 & 1 & 0 & 0 & 1 & 1 & 0 & 1 & 0 & 0 & 0 & 0 & 0 & 1 & 1 \\
\hline 3890 & 25 & L & 0 & 0 & 0 & 0 & 0 & 0 & 1 & 1 & 1 & 1 & 1 & 1 & 1 & 1 & 1 & 0 & 0 \\
\hline 3865 & 25 & $M$ & 0 & 0 & 0 & 0 & 1 & 0 & 1 & 1 & 1 & 1 & 1 & 1 & 1 & 1 & 1 & 1 & 1 \\
\hline 4190 & 25 & $N$ & 0 & 0 & 0 & 0 & 0 & 1 & 1 & 1 & 1 & 1 & 1 & 1 & 1 & 1 & 1 & 1 & 1 \\
\hline ATCC17978 & 77 & nd & 0 & 0 & 0 & 1 & 1 & 1 & 1 & 1 & 0 & 0 & 0 & 0 & 0 & 0 & 0 & 0 & 0 \\
\hline 3909 & 78 & $\mathrm{O}$ & 0 & 0 & 0 & 0 & 0 & 0 & 0 & 1 & 1 & 0 & 0 & 0 & 0 & 0 & 0 & 0 & 0 \\
\hline 3911 & 78 & $\mathrm{O} 1$ & 0 & 0 & 0 & 0 & 0 & 0 & 0 & 1 & 1 & 0 & 0 & 0 & 0 & 0 & 0 & 0 & 0 \\
\hline 3868 & 15 & P & 0 & 1 & 0 & 0 & 1 & 0 & 1 & 1 & 1 & 1 & 1 & 1 & 0 & 0 & 0 & 0 & 1 \\
\hline 3871 & 84 & P1 & 0 & 1 & 0 & 0 & 0 & 0 & 1 & 1 & 0 & 1 & 1 & 1 & 0 & 0 & 0 & 0 & 1 \\
\hline
\end{tabular}

Positive or negative PCR amplification are indicated by 1 or 0 , respectively; nd, not done.

as phages upon appropriate stimuli, and CP3, CP9 and CP14 encode lysozyme. However, none exhibited homology to bacteriophages so far identified in $A$. baumannii $[59,60]$. Few CPs are decorated by morons, accessory genes unnecessary for the virus, which may be helpful for the host bacteria when the prophage is integrated in its genome. Advantage conferred by morons is debated. PapS reductase functions in the assimilatory sulphate reduction pathway, and could serve as a fitness factor under conditions of iron limitation [61], umuDC gene could convey a mutator phenotype on the host [62]. As previously noted [16], the high variability exhibited by prophage sequences suggests recent insertion/ and or rapid loss, and a large pool of phage genomes.

Genotypic characterization of $A$. baumannii isolates during outbreaks occurred in different geographical locations showed the prevalence of clusters of highly similar strains $[4,10]$. Data presented suggest that strains assigned to distinct genotypes according to MLST analysis may harbour specific GEIs. However, variability exists in the distribution of other genomic regions between $A$. baumannii strains assigned to the same genotypes, thus suggesting that horizontal gene transfer and recombination may occur between strains of different genotypes.

The identification of sequences homologous to several GEIs suggests that the genomes of non-baumannii Acinetobacter spp. may function as reservoirs of accessory A. baumannii DNA. Bacteria of the genus Acinetobacter, including $A$. baumannii isolates, are naturally competent [63] and have likely exchanged DNA in evolution. A few GEIs are perfectly conserved in different Acinetobacter species, but many vary in size and content, and have been plausibly remodelled both by recombination and insertional events. Comparative analyses also demonstrated a marked difference in the genome organization of the non-baumannii Acinetobacter sp. baylyi and DR1 relatively to $A$. baumannii.

Differences among $A$. baumannii genomes are also correlated to large strain-specific deletions, which are interestingly associated to selective loss of function. The 3909 strain lacks $m u c K$ and $t c u$ genes which enable the growth on cis, cis-muconate and tricarballylate as sole 
carbon sources $[64,65]$. The 4190 strain lacks tau genes, needed to utilize taurine as a sulphur source in sulphate starvation conditions [36], the AYE and ACICU strains lack genes enabling growth on d-glucarate as sole carbon source [66], the ATCC17978 lacks genes involved in the metabolism of anthranilate, molybdate transport, biosynthesis of the pyrroloquinoline quinone cofactor, chaperone-usher pathway, growth on dicarboxylic acids as the only carbon source [67]. All these large deleted regions can alternatively be viewed as GEIs conserved in the population but missing in one or a few isolates. Sequencing of additional A. baumannii isolates will set the issue.

\section{Conclusions}

The definition of the genome components of A. baumannii provides a scaffold to rapidly evaluate the genomic organization of novel clinical A. baumannii isolates. Distinguishing conserved from accessory components in A. baumannii chromosomes is a functional framework useful for further investigations on the biology and the genetic organization of this species. Changes in island profiling will be useful in genomic epidemiology of $A$. baumannii population. Data provided in this work will facilitate comparisons of $A$. baumannii isolates, and help to define the features of $A$. baumannii as species as to pin down its pathogenic traits.

\section{Methods}

\section{A. baumannii strains}

Comparative genome analysis were performed on whole genome sequences of $A$. baumannii strains AB0057 [GenBank:NC_011586] [16], ACICU [GenBank:NC_010611] [12], ATCC17978 [GenBank:NC_009085] [17] and AYE [GenBank:NC_010410] [18] and draft genome sequences of A. baumannii strains ST2 3990 [GenBank: AEOY00000000], ST25 4190 [GenBank:AEPA00000000] and ST78 3909 [GenBank:AEOZ00000000] strains [11]. The GenBank:CP000521 file, which contains 436 hypothetical proteins putatively encoded by ATCC17978 early annotated as AS1, but not included in the GenBank: NC_009085 file, was also used for comparisons. The genome sequences of non-baumannii Acinetobacter species A. baylyi ADP1 [GenBank:NC_011586], Acinetobacter sp. DR1 [GenBank:NC_014259], A. calcoaceticus RUH2202 [GenBank:ACPK00000000], A. haemolyticus ATCC19194 [GenBank:ADMT00000000], A. johnsonii SH046 [GenBank:ACPL00000000], A. junii SH205 [GenBank: ACPM00000000], A. lwoffii SH145 [GenBank: ACPN00000000], A. radioresistens SK82 [GenBank: ACVR00000000], Acinetobacter sp. ATCC27244 [GenBank:ABYN00000000], A. nosocomialis RUH2624 [GenBank:ACQF00000000] and A. pittii SH024 [GenBank: ADCH00000000] were also used for comparison. The $A$. baumannii strains used in PCR analyses of GEIs have been previously described [10].

\section{Genome analyses}

Gene products putatively encoded by the ST25 4190, ST78 3909 and ST2 3990 strains were identified using xBASE2, comparing the draft genome sequences to the genome of the A. baumannii strain AB0057 used as reference template [11]. The corresponding amino acid sequences are listed in Additional file 7. Predicted ORFs were subsequently compared to the gene products of the wholly sequenced A. baumannii AB0057, ACICU, ATCC and ABAYE strains using MAUVE [15]. Homologies under looked by MAUVE were detected by BLAST and tBLASTn analyses. Gene products encoded by aligned coding regions exhibited at least $50 \%$ identity. $r p o B$ gene sequence analysis for genomic species identification was performed as previously described [3].

\section{PCR analyses}

The conservation of specific GEIs in a set of $A$. baumannii strains was assessed by PCR amplification. PCR reactions were carried out by incubating $20 \mathrm{ng}$ of genomic DNA with $160 \mathrm{ng}$ of each primer in the presence of dXTPs (200 nanomoles), $1.5 \mathrm{mM}$ magnesium chloride and the Taq DNA polymerase Recombinant (Invitrogen). The sequences of the oligomers used as primers, the experimental conditions, the length of the amplimers, the coding regions amplified are all listed in Additional file 8. PCR products were electrophoresed on 1.5$2 \%$ agarose gels in $0.5 \times \mathrm{TBE}$ buffer $(45 \mathrm{mM}$ Tris $\mathrm{pH} 8$, $45 \mathrm{mM}$ Borate, $0.5 \mathrm{mM}$ EDTA) at $120 \mathrm{~V}$ (constant voltage). The $100 \mathrm{bp}$ ladder (Promega) was used as molecular weight marker.

The co-linearity of contigs and the DNA content of the corresponding chromosomal regions were assessed by sequencing PCR products bridging contig ends.

\section{Additional material}

Additional file 1: Structures of plasmids identified in ST2 3990,

ST25 4190 and ST78 3909 strains. the figure shows the circular maps of plasmids p1ABST2, p2ABST2, p1ABST25, p2ABST25 and p1ABST78 with relevant features. ORFs and direction of the transcription are represented by arrow-shaped boxes. Plasmid sizes and names of various features are reported.

Additional file 2: Coding capacity of plasmids carried by strains 39093990 and 4190 . the table lists ORFs of plasmids P1ABST2, p2ABST2, p1ABST25, p2ABST25 and p1ABST78. Position, number of amino acids and putative function are reported for each ORF.

Additional file 3: Target site duplications. sequences duplicated at the ends of GEls upon genome integration are listed in the table. Base changes in left and right TSDs are marked according to IUB codes. Residues missing in one TSD are in parenthesis. Known target genes are indicated.

Additional file 4: GEls organization and ORFs content the 63 sheets of the EXCEL file correspond to the 63 genomic loci carrying GEls shown 
in Figure 2. The ORF number, the amino acid length and the hypothesized function are given in each sheet. For draft genomes, the corresponding contigs are indicated. Identical or closely related ORFs present in different GEls are positioned in the same row and labelled by the same colour to facilitate view. ORFs denoted as tb were identified by tBLASTn analyses. Grey and orange bars denote closely located ORFs putatively co-expressed. Homologous coding regions are boxed when a single ORF in one strain corresponds to two or more contiguous ORFs in others.

\section{Additional file 5: Micro-heterogeneity regions. coding regions} present/absent in the compared A. baumannnii genomes, denoted in the text as mhrs (micro-heterogeneity regions), and their hypothetical function, are listed in the table. Alternative regions present at the same locus are marked by different colour characters. mhrs containing two or more ORFs are boxed.

Additional file 6: Cryptic prophages. structures of cryptic prophages identified in A. baumannii genomes. Prophage types are boxed to highlight their relatedness as resulting from MAUVE alignment. Different CP1 and CP2 are shown to illustrate the degree of genetic variation of $A$. baumannii prophage families.

Additional file 7: Gene products putatively encoded by strains 4190, 3909 and 3990. ORFs of strains 4190, 3909 and 3990 and the corresponding contig number are shown.

Additional file 8: Genomic regions, amplified genes, primers, amplicon sizes and cycling conditions used in PCR surveys. (none, title sufficiently describes data).

\section{Acknowledgements}

We thank all colleagues who generously provided strains included in the study: Antonella Agodi, Matteo Bassetti, Susanna Cuccurullo, Ziad Daoud, Athanassios Tsakris, and Haluk Vahaboglu.

This work was supported in part by grants from Agenzia Italiana del Farmaco, Italy (AIFA2007 contract no. FARM7X9F8K) and from Ministero dell'Istruzione, dell'Universita'e della Ricerca, Italy (PRIN 2008 to RZ, PRIN 2009 to PPDN). The funders had no role in study design, data collection and analysis, decision to publish, or preparation of the manuscript.

\section{Author details}

'Dipartimento di Biologia e Patologia Cellulare e Molecolare, Università Federico II, Via S. Pansini 5, 80131 Napoli, Italy. ${ }^{2}$ Dipartimento di Scienze Mediche Preventive, Sezione di Igiene, Università Federico II, Via S. Pansini 5 , 80131 Napoli, Italy.

\section{Authors' contributions}

Conceived and designed the experiments: PPDN, FR, MG, MT, and RZ. Performed the experiments and analyzed the data: FR, PPDN, and MG. Wrote the paper: PPDN and RZ. All authors read and approved the final manuscript.

\section{Competing interests}

The authors declare that they have no competing interests.

Received: 4 May 2011 Accepted: 10 October 2011

Published: 10 October 2011

\section{References}

1. Dijkshoorn L, Nemec A, Seifert H: An increasing threat in hospitals: multidrugresistant Acinetobacter baumannii. Nat Rev Microbiol 2007, 5:939-951.

2. Durante-Mangoni E, Zarrilli R: Global spread of drug-resistant Acinetobacter baumannii: molecular epidemiology and management of antimicrobial resistance. Future Microbiol 2011, 6:407-422.

3. Nemec A, Krizova L, Maixnerova M, van der Reijden TJ, Deschaght $P$, Passet V, Vaneechoutte M, Brisse S, Dijkshoorn L: Genotypic and phenotypic characterization of the Acinetobacter calcoaceticusAcinetobacter baumannii complex with the proposal of Acinetobacter pittii sp. nov. (formerly Acinetobacter genomic species 3 ) and
Acinetobacter nosocomialis sp. nov. (formerly Acinetobacter genomic species 13TU). Res Microbiol 2011, 162:393-404.

4. Higgins PG, Dammhayn C, Hackel M, Seifert H: Global spread of carbapenem-resistant Acinetobacter baumannii. J Antimicrob Chemother 2010, 65:233-238.

5. Van Dessel H, Dijkshoorn L, van der Reijden T, Bakker N, Paauw A, van den Broek P, Verhoef J, Brisse S: Identification of a new geographically widespread multiresistant Acinetobacter baumannii clone from European hospitals. Res Microbiol 2004, 155:105-112

6. Dijkshoorn L, Aucken H, Gerner-Smidt P, Janssen P, Kaufmann ME, Garaizar J, Ursing J, Pitt TL: Comparison of outbreak and nonoutbreak Acinetobacter baumannii strains by genotypic and phenotypic methods. J Clin Microbiol 1996, 34:1519-1525.

7. Wisplinghoff H, Hippler C, Bartual SG, Haefs C, Stefanik D, Higgins PG, Seifert H: Molecular epidemiology of clinical Acinetobacter baumannii and Acinetobacter genomic species 13TU isolates using a multilocus sequencing typing scheme. Clin Microbiol Infect 2008, 14:708-715.

8. Diancourt L, Passet V, Nemec A, Dijkshoorn L, Brisse S: The population structure of Acinetobacter baumannii: expanding multiresistant clones from an ancestral susceptible genetic pool. PLOS One 2010, 5:e10034.

9. Turton JF, Gabriel SN, Valderrey C, Kaufmann ME, Pitt TL: Use of sequencebased typing and multiplex PCR to identify clonal lineages of outbreak strains of Acinetobacter baumannii. Clin Microbiol Infect 2007, 13:807-815.

10. Di Popolo A, Giannouli M, Triassi M, Brisse S, Zarrilli R: Molecular epidemiological investigation of multidrug-resistant Acinetobacter baumannii strains in four Mediterranean countries with a multilocus sequence typing scheme. Clin Microbiol Infect 2011, 17:197-201.

11. Zarrilli R, Giannouli M, Rocco F, Loman NJ, Haines AS, Constantinidou C, Pallen MJ, Triassi M, Di Nocera PP: Genome sequences of three Acinetobacter baumannii strains assigned to ST2, ST25 and ST78 multilocus sequencing typing genotypes. J Bacteriol 2011, 193:2359-2360.

12. Iacono M, Villa L, Fortini D, Bordoni R, Imperi F, Bonnal RJ, SicheritzPonten T, De Bellis G, Visca P, Cassone A, Carattoli A: Whole-genome pyrosequencing of an epidemic multidrug-resistant Acinetobacter baumannii strain belonging to the European clone II group. Antimicrob Agents Chemother 2008, 52:2616-2625.

13. Bertini A, Poirel L, Mugnier PD, Villa L, Nordmann P, Carattoli A: Characterization and PCR-based replicon typing of resistance plasmids in Acinetobacter baumannii. Antimicrob Agents Chemother 2010, 54:4168-4177.

14. Merino M, Acosta J, Poza M, Sanz F, Beceiro A, Chaves F, Bou G: OXA-24 carbapenemase gene flanked by XerC/XerD-like recombination sites in different plasmids from different Acinetobacter species isolated during a nosocomial outbreak. Antimicrob Agents Chemother 2010, 54:2724-2727.

15. Darling AE, Mau B, Perna NT: progressiveMauve: multiple genome alignment with gene gain, loss, and rearrangement. PLOS One 2010, 5 e11147.

16. Adams MD, Goglin K, Molyneaux N, Hujer KM, Lavender H, Jamison J J, MacDonald IJ, Martin KM, Russo T, Campagnari AA, Hujer AM, Bonomo RA Gill SR: Comparative genome sequence analysis of multidrug-resistant Acinetobacter baumannii. J Bacteriol 2008, 190:8053-8064.

17. Smith MG, Gianoulis TA, Pukatzki S, Mekalanos JJ, Ornston LN, Gerstein M, Snyder M: New insights into Acinetobacter baumannii pathogenesis revealed by high-density pyrosequencing and transposon mutagenesis. Genes Dev 2007, 21:601-614.

18. Vallenet $D$, Nordmann $P$, Barbe V, Poirel L, Mangenot $S$, Bataille E, Dossat $C$, Gas S, Kreimeyer A, Lenoble P, Oztas S, Poulain J, Segurens B, Robert C, Abergel C, Claverie JM, Raoult D, Médigue C, Weissenbach J, Cruveiller S: Comparative analysis of Acinetobacters: three genomes for three lifestyles. PLOS ONE 2008, 3:e1805.

19. Gaddy JA, Tomaras AP, Actis LA: The Acinetobacter baumannii 19606 OmpA protein plays a role in biofilm formation on abiotic surfaces and in the interaction of this pathogen with eukaryotic cells. Infect Immun 2009, 77:3150-3160.

20. Lee JS, Choi CH, Kim JW, Lee JC: Acinetobacter baumannii outer membrane protein A induces dendritic cell death. J Microbiol 2010, 48:387-392.

21. Russo TA, MacDonald U, Beanan JM, Olson R, MacDonald IJ, Sauberan SL, Luke NR, Schultz LW, Umland TC: Penicillin-binding protein $7 / 8$ contributes to the survival of Acinetobacter baumannii in vitro and in vivo. J Infect Dis 2009, 199:513-521. 
22. Jacobs AC, Hood I, Boyd KL, Olson PD, Morrison JM, Carson S, Sayood K, Iwen PC, Skaar EP, Dunman PM: Inactivation of phospholipase D diminishes Acinetobacter baumannii pathogenesis. Infect Immun 2010, 78:1952-1962

23. Russo TA, Luke NR, Beanan JM, Olson R, Sauberan SL, MacDonald U, Schultz LW, Umland TC, Campagnari AA: The K1 capsular polysaccharide of Acinetobacter baumannii strain 307-0294 is a major virulence factor. Infect Immun 2010, 78:3993-4000.

24. Tomaras AP, Dorsey CW, Edelmann RE, Actis L: Attachment to and biofilm formation on abiotic surfaces by Acinetobacter baumannii: involvement of a novel chaperone-usher pili assembly system. Microbiology 2003, 149:3473-3484

25. Zimbler DL, Penwell WF, Gaddy JA, Menke SM, Tomaras AP, Connerly PL, Actis LA: Iron acquisition functions expressed by the human pathogen Acinetobacter baumannii. Biometals 2009, 22:23-32.

26. Coyne $S$, Courvalin P, Périchon B: Efflux-mediated antibiotic resistance in Acinetobacter spp. Antimicrob Agents Chemother 2011, 55:947-953.

27. Barbe V, Vallenet D, Fonknechten N, Kreimeyer A, Oztas S, Labarre L, Cruveiller S, Robert C, Duprat S, Wincker P, Ornston LN, Weissenbach J, Marlie're P, Cohen GN, Me'digue C: Unique features revealed by the genome sequence of Acinetobacter sp. ADP1, a versatile and naturally transformation competent bacterium. Nucleic Acids Res 2004, 32:5766-5779

28. Dobrindt U, Hochhut B, Hentschel U, Hacker J: Genomic islands in pathogenic and environmental microorganisms. Nat Rev Microbiol 2004, 2:414-424

29. Sridhar J, Narmada SR, Sabarinathan R, Ou HY, Deng Z, Sekar K, Rafi ZA, Rajakumar K: sRNAscanner: a computational tool for intergenic small RNA detection in bacterial genomes. PLoS One 2010, 5:e11970.

30. Post V, White PA, Hall R: Evolution of AbaR-type genomic resistance islands in multiply antibiotic-resistant Acinetobacter baumannii. $J$ Antimicrob Chemother 2010, 65:1162-1170.

31. Nuccio SP, Bäumler AJ: Evolution of the chaperone/usher assembly pathway: fimbrial classification goes Greek. Microbiol Mol Biol Rev 2007, 71:551-575.

32. Barnhart MM, Chapman MR: Curli biogenesis and function. Annu Rev Microbiol 2006, 60:131-147.

33. Locht C, Bertin P, Menozzi FD, Renauld G: The filamentous haemagglutinin, a multifaceted adhesion produced by virulent Bordetella spp. Mol Microbiol 1993, 9:653-460.

34. Rocco F, De Gregorio E, Colonna B, Di Nocera PP: Stenotrophomonas maltophilia genomes: a start-up comparison. Int J Med Microbiol 2009, 299:535-546.

35. Zhang YM, Rock CO: Membrane lipid homeostasis in bacteria. Nature Rev Microb 2008, 6:222-232.

36. van der Ploeg JR, Iwanicka-Nowicka R, Bykowski T, Hryniewicz M, Leisinger T: The Escherichia coli ssuEADCB gene cluster is required for the utilization of sulfur from aliphatic sulfonates and is regulated by the transcriptional activator Cbl. J Biol Chem 1999, 274:29358-29365.

37. Frankenberg-Dinkel N: Bacterial heme oxygenases. Antioxidants \& Redox Signaling 2004, 6:825-834.

38. Braun V, Mahren S, Sauter A: Gene regulation by transmembrane signaling. Biometals 2006, 19:103-113.

39. Xu Y, Chen M, Zhang W, Lin M: Genetic organization of genes encoding phenol hydroxylase, benzoate 1,2-dioxygenase alpha subunit and its regulatory proteins in Acinetobacter calcoaceticus PHEA-2. Curr Microbiol 2003, 46:235-240.

40. Zhou NY, Fuenmayor SL, Williams PA: nag genes of Ralstonia (formerly Pseudomonas) sp. strain U2 encoding enzymes for gentisate catabolism. J Bacteriol 2001, 183:700-708.

41. Díaz E, Ferrández A, Prieto MA, García JL: Biodegradation of aromatic compounds by Escherichia coli. Microbiol Mol Biol Rev 2001, 65:523-569.

42. Hendrix RW, Lawrence JG, Hatfull GF, Casjens S: The origins and ongoing evolution of viruses. Trends Microbiol 2000, 8:504-508.

43. Permina EA, Mironov AA, Gelfand MS: Damage-repair error-prone polymerases of eubacteria: association with mobile genome elements. Gene 2002, 293:133-140.

44. Eppinger M, Rosovitz MJ, Fricke WF, Rasko DA, Kokorina G, Fayolle C, Lindler LE, Carniel E, Ravel J: The complete genome sequence of Yersinia pseudotuberculosis IP31758, the causative agent of Far East scarlet-like fever. PLOS Genet 2007, 3:e142.
45. Cariss SJ, Constantinidou C, Patel MD, Takebayashi Y, Hobman JL, Penn CW, Avison MB: YieJ (CbrC) mediates CreBC-dependent colicin E2 tolerance in Escherichia coli. J Bacteriol 2010, 192:3329-3336.

46. Genschik P, Drabikowski K, Filipowicz W: Characterization of the Escherichia coli RNA 3'-terminal phosphate cyclase and its sigma54regulated operon. J Biol Chem 1998, 273:25516-25526.

47. Redko Y, de la Sierra-Gallay, Condon C: When all's zed and done: the structure and function of RNase $\mathbf{Z}$ in prokaryotes. Nature Rev Microbio 2007, 5:278-286.

48. Horvath P, Barrangou R: CRISPR/Cas, the immune system of Bacteria and Archaea. Science 2010, 327:167-170.

49. Godde JS, Bickerton A: The repetitive DNA elements called CRISPRs and their associated genes: evidence of horizontal transfer among prokaryotes. J Mol Evol 2006, 62:718-729.

50. Wang YD, Zhao S, Hill CW: Rhs elements comprise three subfamilies which diverged prior to acquisition by Escherichia coli. J Bacteriol 1998, 180:4102-4110.

51. Bernier SP, Sokol PA: Use of suppression-subtractive hybridization to identify genes in the Burkholderia cepacia complex that are unique to Burkholderia cenocepacia. J Bacteriol 2005, 187:5278-5291.

52. Bingle LEH, Bailey CE, Pallen MJ: Type VI secretion: a beginner's guide. Curr Opin Microbiol 2008, 11:3-8.

53. Pukatzki S, Ma AT, Revel AT, Sturtevant D, Mekalanos JJ: Type VI secretion system translocates a phage tail spike-like protein into target cells where it cross-links actin. Proc Natl Acad Sci USA 2007, 104:15508-15513.

54. Jung J, Baek JH, Park W: Complete genome sequence of diesel-degrading Acinetobacter sp. DR1. J Bacteriol 2010, 192:4794-4795.

55. Dobrindt U, Chowdary MG, Krumbholz G, Hacker J: Genome dynamics and its impact on evolution of Escherichia coli. Med Microbiol Immunol 2010, 199:145-154

56. Ernst RK, D'Argenio DA, Ichikawa JK, Bangera MG, Selgrade $\mathrm{S}$, Jane L, Burns JL, Hiatt P, McCoy K, Brittnacher M, Kas A, Spencer DH, Olson MV, Ramsey BW, Lory S, Miller SI: Genome mosaicism is conserved but not unique in Pseudomonas aeruginosa isolates from the airways of young children with cystic fibrosis. Environ Microbiol 2003, 5:1341-1349.

57. Cronan JE: Phospholipid modifications in bacteria. Curr Opin Microbiol 2002, 5:202-205.

58. Shen S, Mascarenhas M, Morgan R, Rahn K, Karmali MA: Identification of four fimbria-encoding genomic islands that are highly specific for verocytotoxin-producing Escherichia coli serotype 0157 strains. J Clin Microbiol 2005, 43:3840-3850.

59. Yang $H$, Liang $L$, Lin $S$, Jia S: Isolation and characterization of a virulent bacteriophage AB1 of Acinetobacter baumannii. BMC Microbiol 2010, 10:131.

60. Lin NT, Chiou PY, Chang KC, Chen LK, Lai MJ: Isolation and characterization of phi AB2: a novel bacteriophage of Acinetobacter baumannii. Res Microbiol 2010, 161:308-314.

61. Ronning CM, Losada L, Brinkac L, Inman J, Ulrich RL, Schell M, Nierman WC, DeShazer D: Genetic and phenotypic diversity in Burkholderia: contributions by prophage and phage-like elements. BMC Microbio/ 2010, 10:202.

62. Venter JC, Remington K, Heidelberg JF, Halpern AL, Rusch D, Eisen JA Wu D, Paulsen I, Nelson KE, Nelson W, Fouts DE, Levy S, Knap AH, Lomas MW, Nealson K, White O, Peterson J, Hoffman J, Parsons R, BadenTillson $\mathrm{H}$, Pfannkoch C, Rogers $\mathrm{YH}$, Smith HO: Environmental genome shotgun sequencing of the Sargasso Sea. Science 2004, 304:66-74.

63. Ramirez MS, Don M, Merkier AK, Bistué AJ, Zorreguieta A, Daniela Centrón D, Tolmasky ME: Naturally competent Acinetobacter baumannii clinical isolate as a convenient model for genetic studies. J Clin Microbiol 2010, 48:1488-1490.

64. Williams PA, Shaw LE: mucK, a gene in Acinetobacter calcoaceticus ADP1 (BD413), encodes the ability to grow on exogenous cis, cis-muconate as the sole carbon source. J Bacteriol 1997, 179:5935-5942.

65. Lewis JA, Horswill AR, Schwem BE, Escalante-Semerena JC: The tricarballylate utilization (tcuRABC) genes of Salmonella enterica serovar Typhimurium LT2. J Bacteriol 2004, 186:1629-1637.

66. Aghaie A, Lechaplais C, Sirven P, Tricot S, Besnard-Gonnet M, Muselet D, de Berardinis V, Kreimeyer A, Gyapay G, Salanoubat M, Perret A: New insights into the alternative D-glucarate degradation pathway. J Biol Chem 2001 283:15638-15646. 
67. Parke D, Garcia MA, Ornston LN: Cloning and genetic characterization of dca genes required for beta-oxidation of straight-chain dicarboxylic acids in Acinetobacter sp. strain ADP1. Appl Environ Microbiol 2001, 67:4817-4827.

doi:10.1186/1471-2180-11-224

Cite this article as: Di Nocera et al:: Genome organization of epidemic

Acinetobacter baumannii strains. BMC Microbiology 2011 11:224.

Submit your next manuscript to BioMed Central and take full advantage of:

- Convenient online submission

- Thorough peer review

- No space constraints or color figure charges

- Immediate publication on acceptance

- Inclusion in PubMed, CAS, Scopus and Google Scholar

- Research which is freely available for redistribution

Submit your manuscript at www.biomedcentral.com/submit

() BioMed Central 